\title{
Investigation of a Tricarbide Grooved
} Ring Fuel Element for a Nuclear Thermal Rocket

Brian Taylor

Dr. Bill Emrich

Dr. Dennis Tucker

Marvin Barnes

NASA MSFC
Nicolas Donders

Kettering University

Kelsa Benensky

University of Tennessee

$7 / 11 / 2017$ 


\section{Outline}

- Background

- Introduction

- Modeling

- Neutronics

- Fluid/Thermal

- Fabrication Experiments

- material selection

- Process

- Material Characterization

- Path Forward 


\section{Background}

\section{- Nuclear Propulsion}

- Nuclear Thermal is far more efficient than chemical engines

- Nuclear power allows for high Isp while maintaining high thrust

- Propulsion system efficiency, mass, and thrust have a large impact upon mission logistics and cost

\section{- Traditional Reactor Elements}

- Hexagonal rods with straight axial flow passages

- Cermet or graphite based

- Particle Beds attempted

- Much larger surface area

- thermal instabilities/hot spots
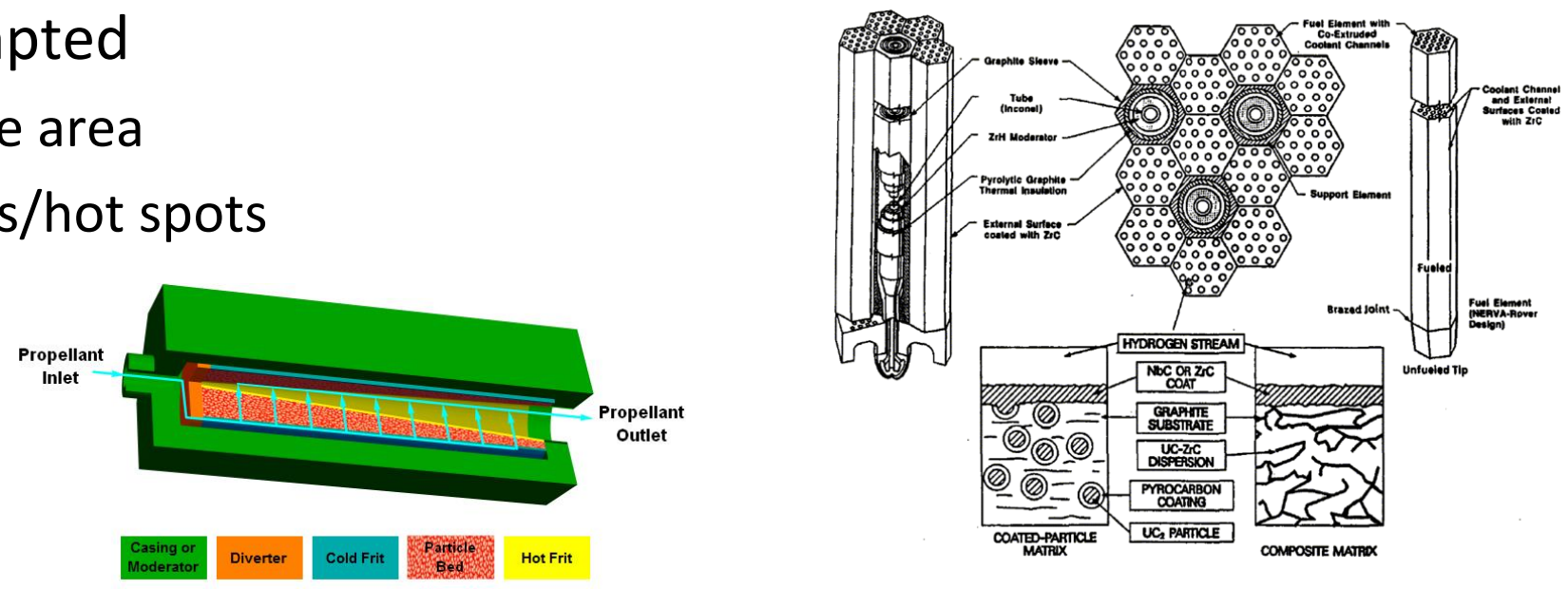


\section{年 Grooved Ring Fuel Element}

\section{- New fuel element concept}

- Stacked grooved disks designed to increase surface area and heat transfer to propellant

- Leading to higher thrust/weight engines

- Propellant flows from outer to inner diameter of disks which heat the propellant

- Stack of disks makes an element

- Cluster of elements in a reactor

- Carbide materials (e.g. UC, NbC, ZrC)

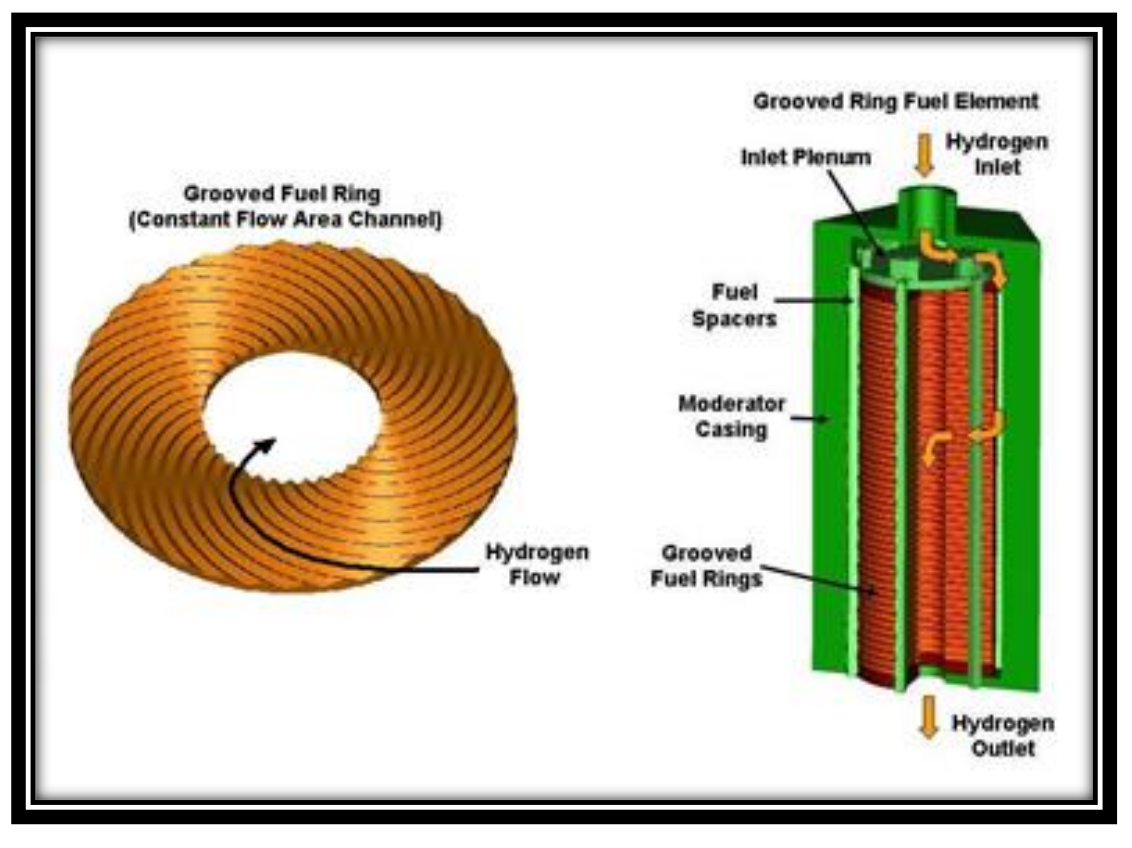

- Mixture has higher melting point than traditional fuel forms

- Result: hotter propellant and greater thrust/efficiency 


\section{NEUTRONICS MODELING}




\section{Neutronics Modeling}

\section{- Purpose}

- Develop a concept reactor layout for a set thrust goal

- Power and distribution

- Analyze impact of material selection upon nuclear reactions

- Study relative material quantities

- Determine uranium enrichment and quantities required

- Relate to theoretical density 


\section{Reactor Design}

\section{NTR Reactor Configuration Using (U-Zr-Nb)C Fuel}

$25 \mathrm{~K}$ Thrust $-8 \mathrm{~kW} / \mathrm{cm}^{3}$-- Optimal Fuel to Moderator Ratio $=0.261$
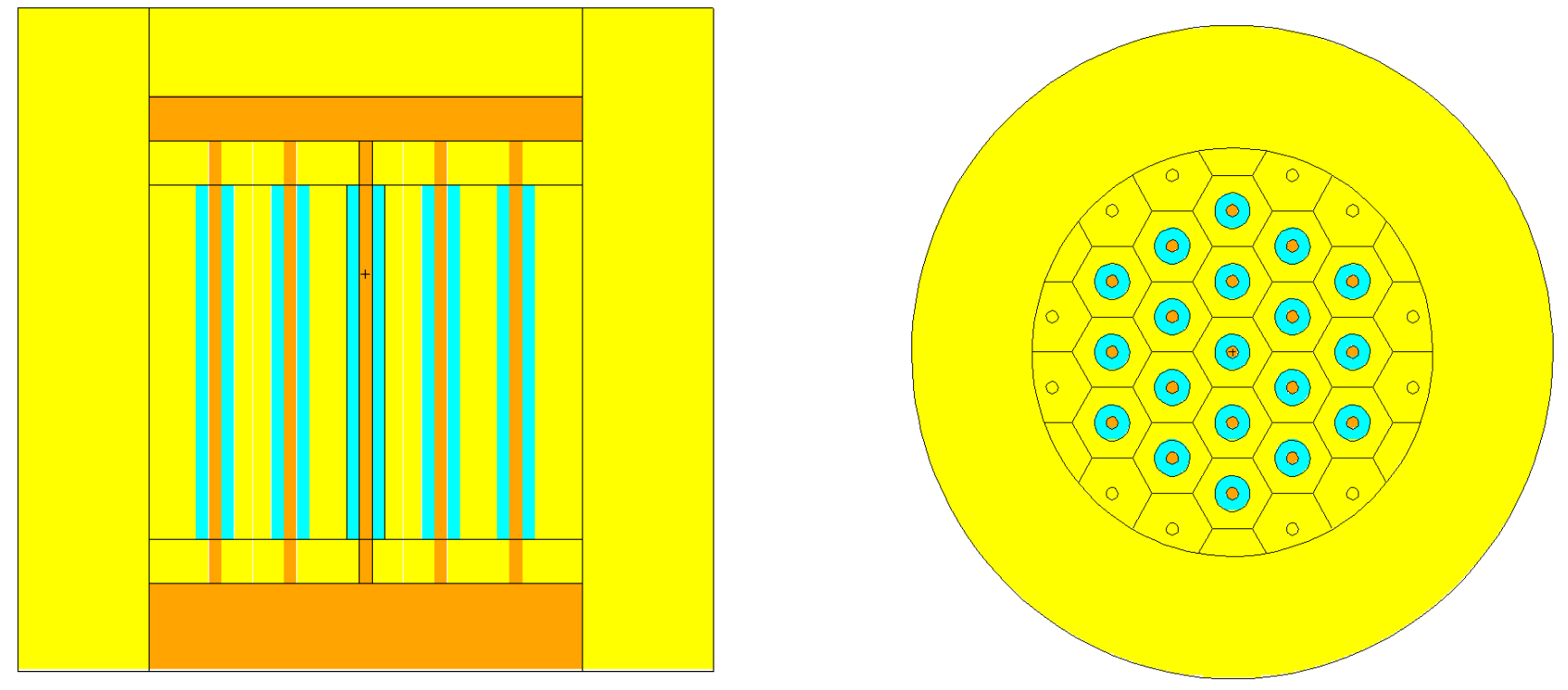

Beryllium

Fuel 


\section{Reactor Design}

\section{NTR Reactor Configuration Using (U-Zr-Ta)C Fuel}

25K Thrust -- 8 kW/cm3 -- Optimal Fuel to Moderator Ratio = 2.95
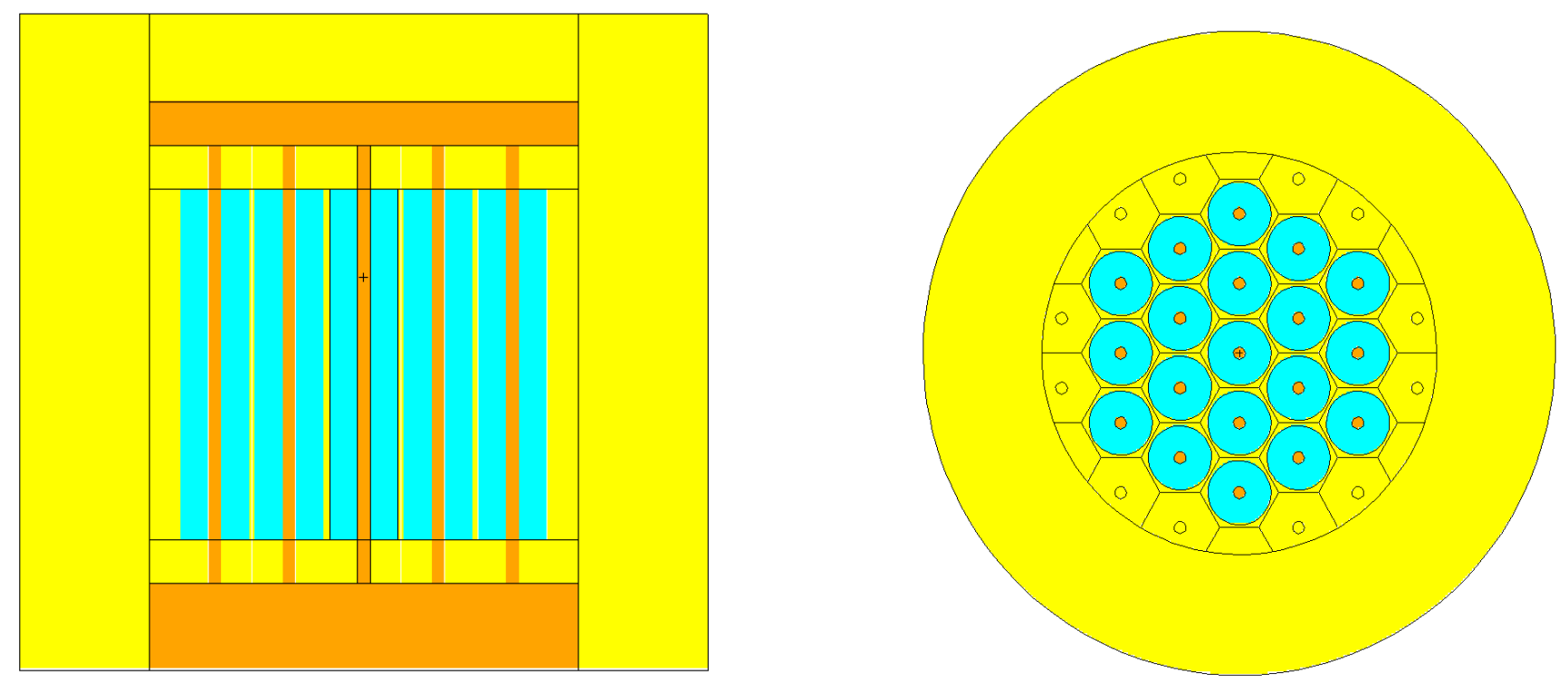


\section{量 Neutronics Modeling}

\section{Uranium Carbide Material Neutron Absorption Cross-Sections}

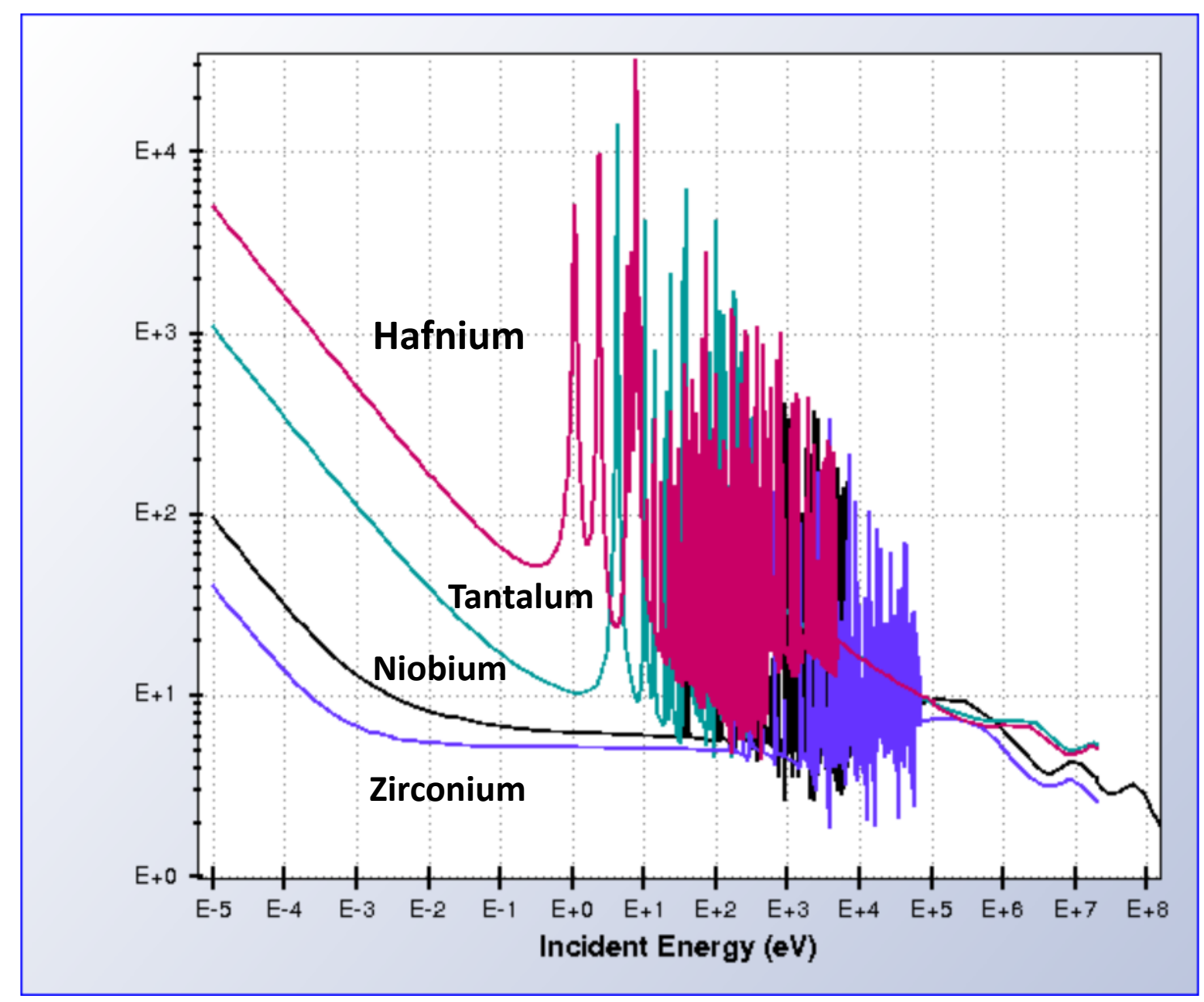




\section{Neutronics Modeling}

Uranium Carbide Requirements for Criticality

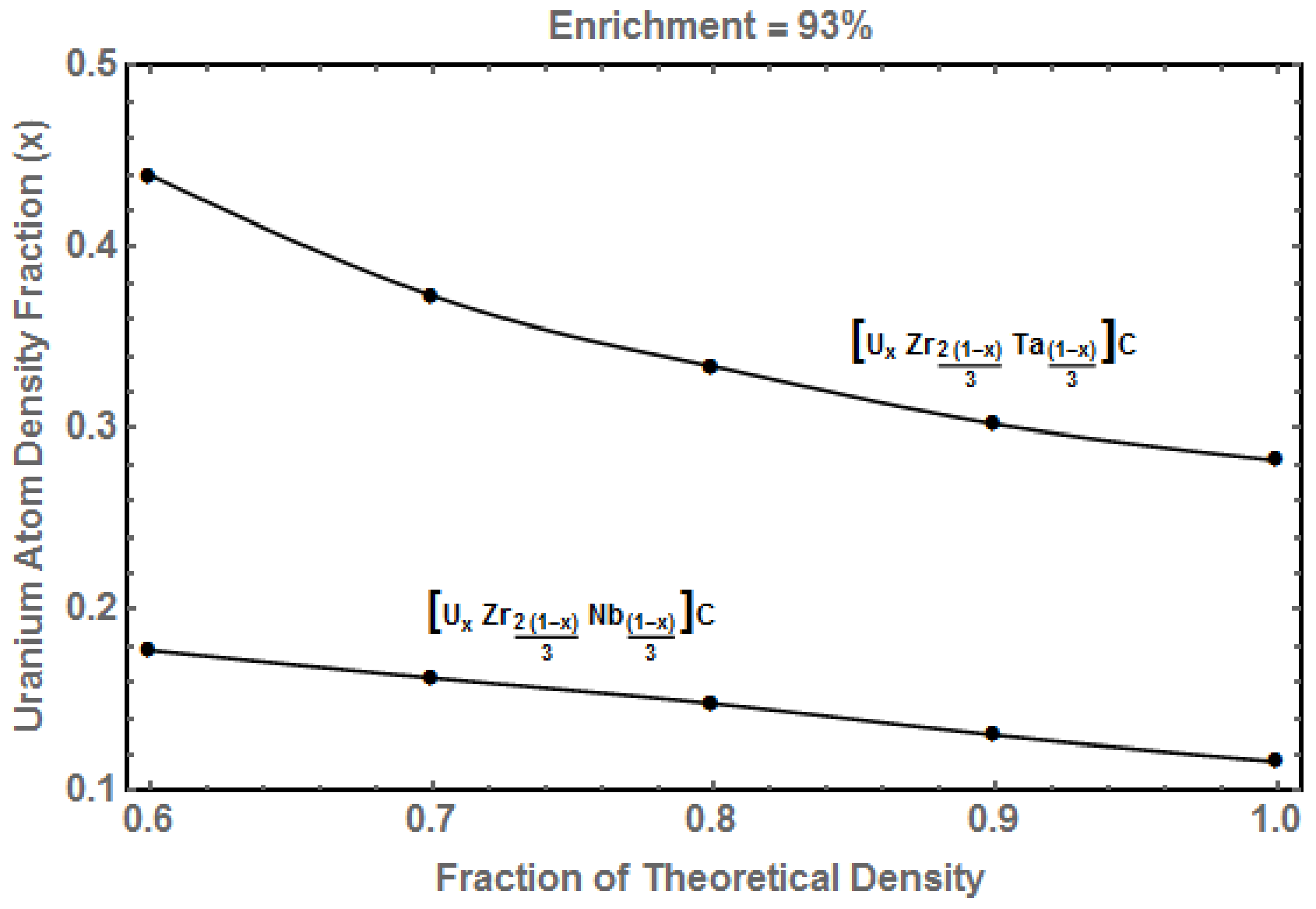

- Grooves and porosity decrease overall density requiring additional UC for reactivity 


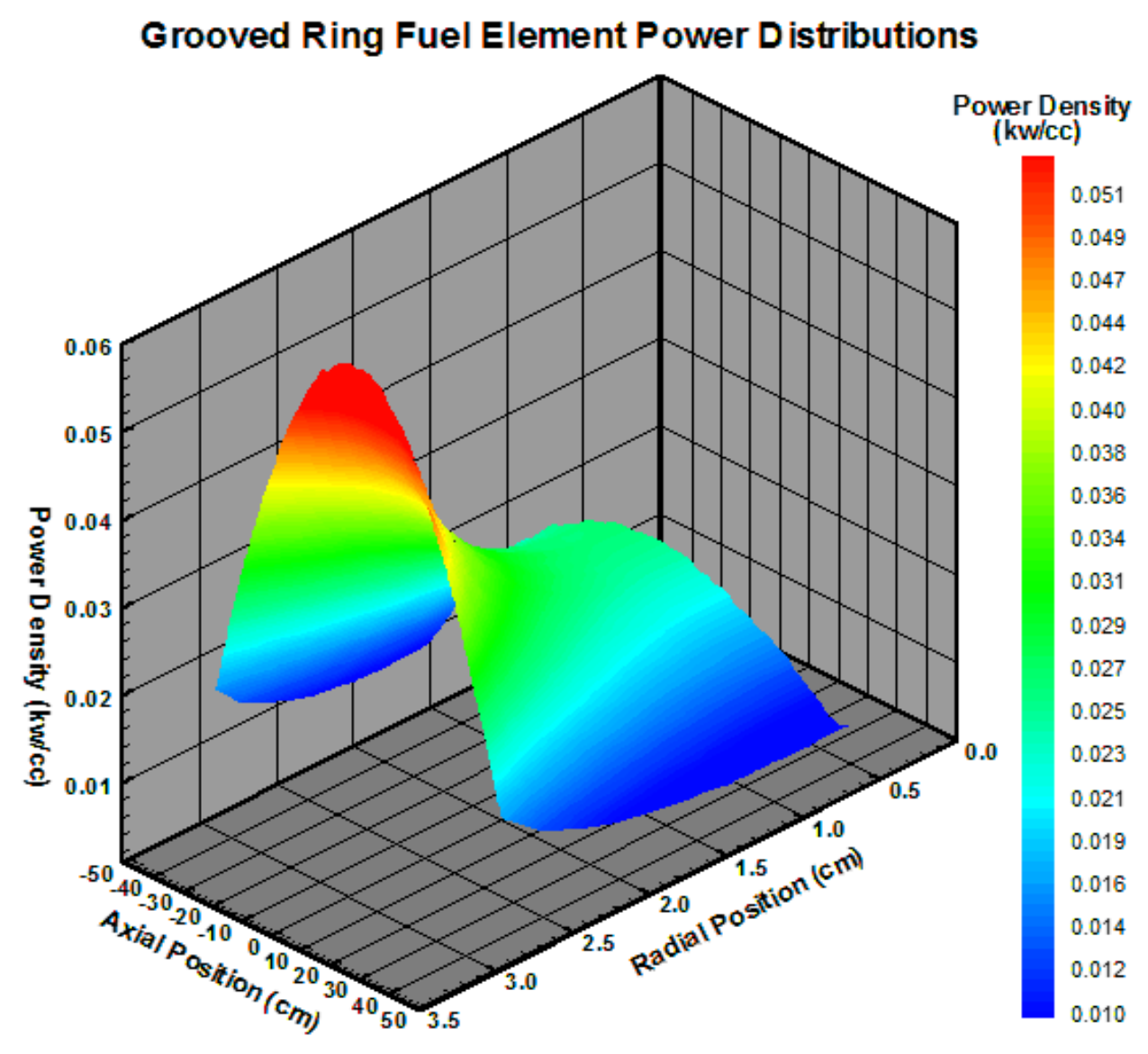

- Power peaking profile of a grooved ring fuel element

- Modest power peaking seen so far 
THERMAL FLUID MODEL 


\section{Thermal Fluid Model}

- Shortened element modeled ( 2 rings)

- Comsol

- Beryllium structure with zirconium carbide rings

- Properties of mixtures not yet developed for model

- Boundary conditions varied to determine appropriate pressure delta to heat the flow for a given power/volume of $8 \mathrm{~kW} / \mathrm{cm}^{3}$

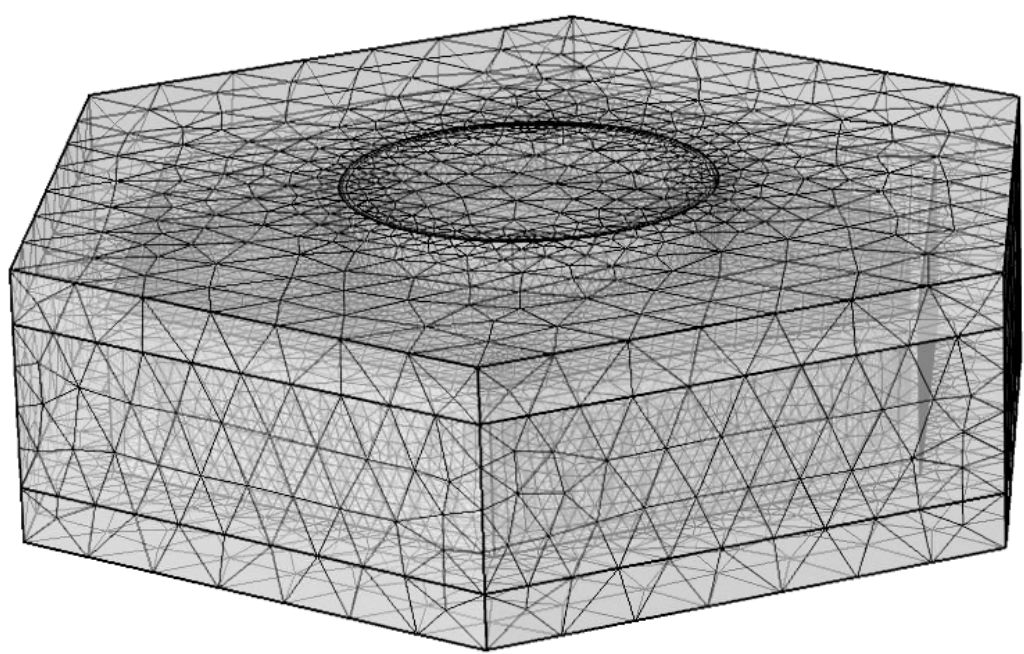




\section{Temperature}
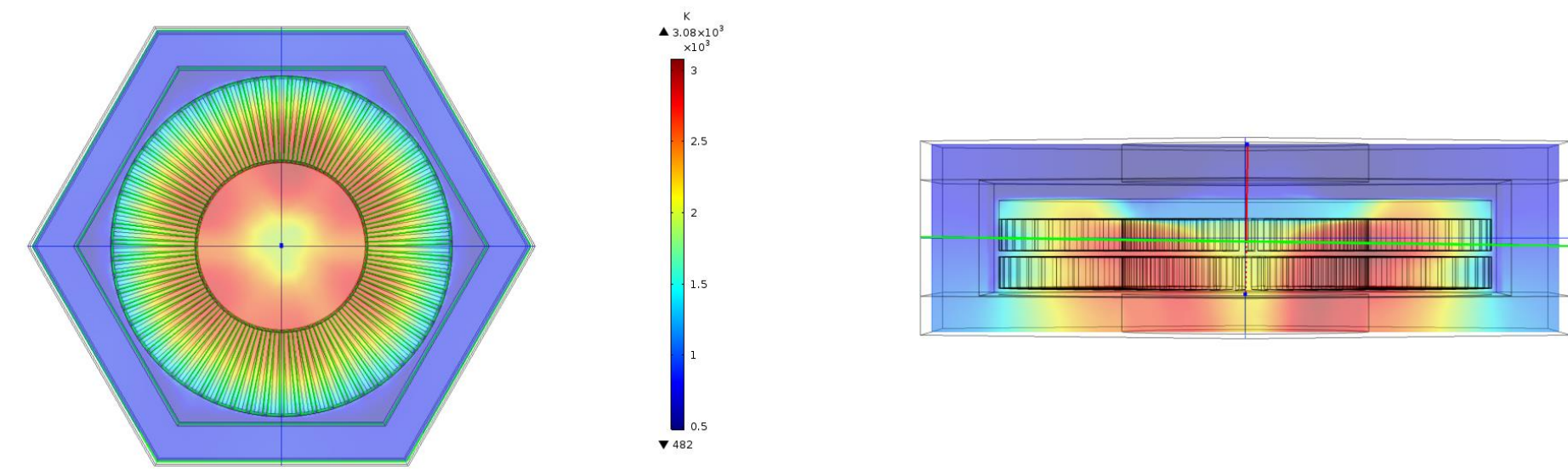

- 4 psi seems to drive the flow at the right flow rate to heat it to near $3000 \mathrm{~K}$ for $8 \mathrm{~kW} / \mathrm{cm}^{3}$

- Cold spots exist due to cooling from the top cover of the rings, but would be reduced in a full stack with mixing and additional heated propellant 


\section{量 Velocity}
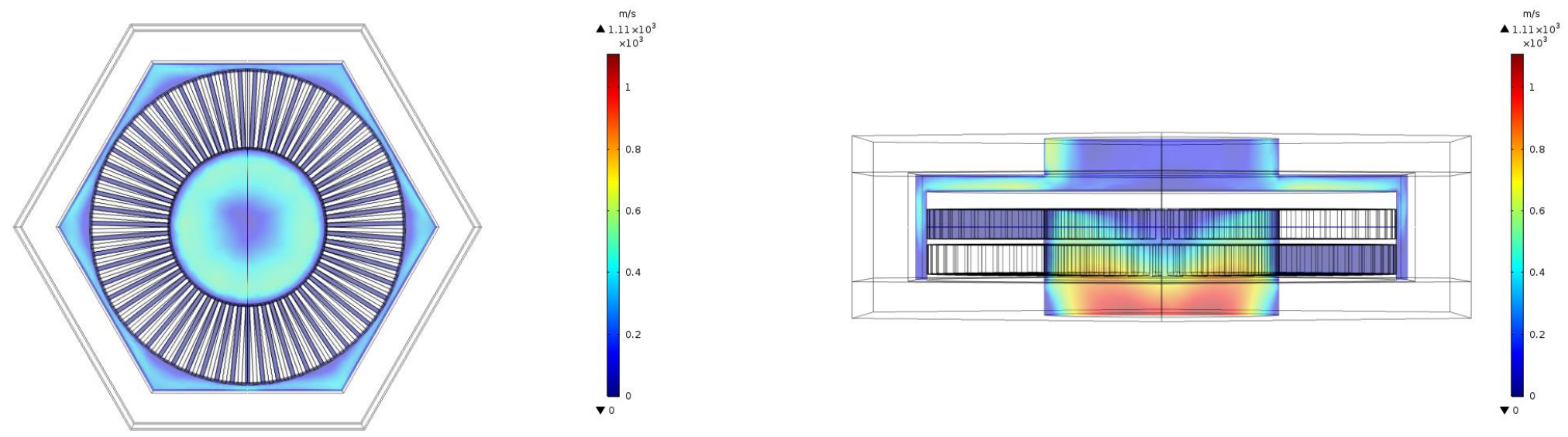

- Velocity of $\mathrm{H}_{2}$ through the element is fairly slow along the outer radius and through the grooves but inceases in the central cavity while mixing but remaining laminar 


\section{FABRICATION EXPERIMENTS}




\section{Selection of Materials}

\section{- Material Selection}

- Need high melting temperature and low neutron cross section (except uranium)

- NbC and ZrC chosen

- Lower neutron cross section than HC or TC

- Uranium Carbide Surrogate

- Substitute for uranium

- Avoid regulatory hurdles

- Vanadium Carbide chosen

- Similar crystal structure

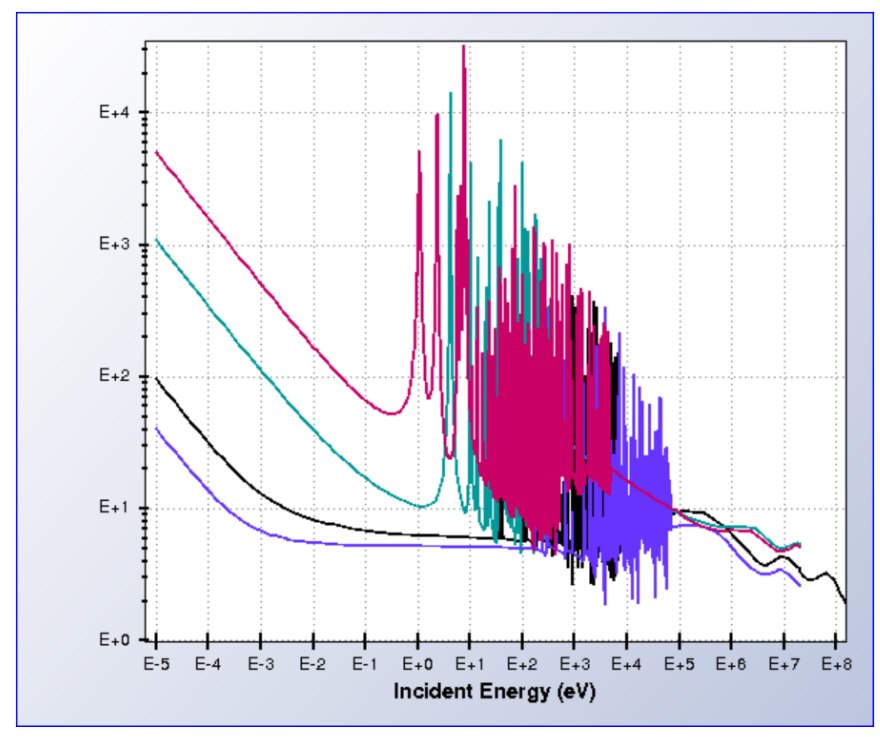




\section{Process}

- Grind materials to uniform particle size

- Spark Plasma Sintering

- Powder compressed at high pressure in die

- High current passed through die

- Control dwell, rise and cooling times as well as temperatures

- Trying to reach high theoretical density

- Porosity reduces reactivity and could lead to hydrogen reactions with the uranium

- Goal

- Achieve a uniform distribution in a solid solution, ultimately with low porosity

- Best to date: $98 \%$ theoretical density

- Grooves

- Test grooves cut with saw

- Looking for best way to cut grooves

- Attempting to try to use a water jet
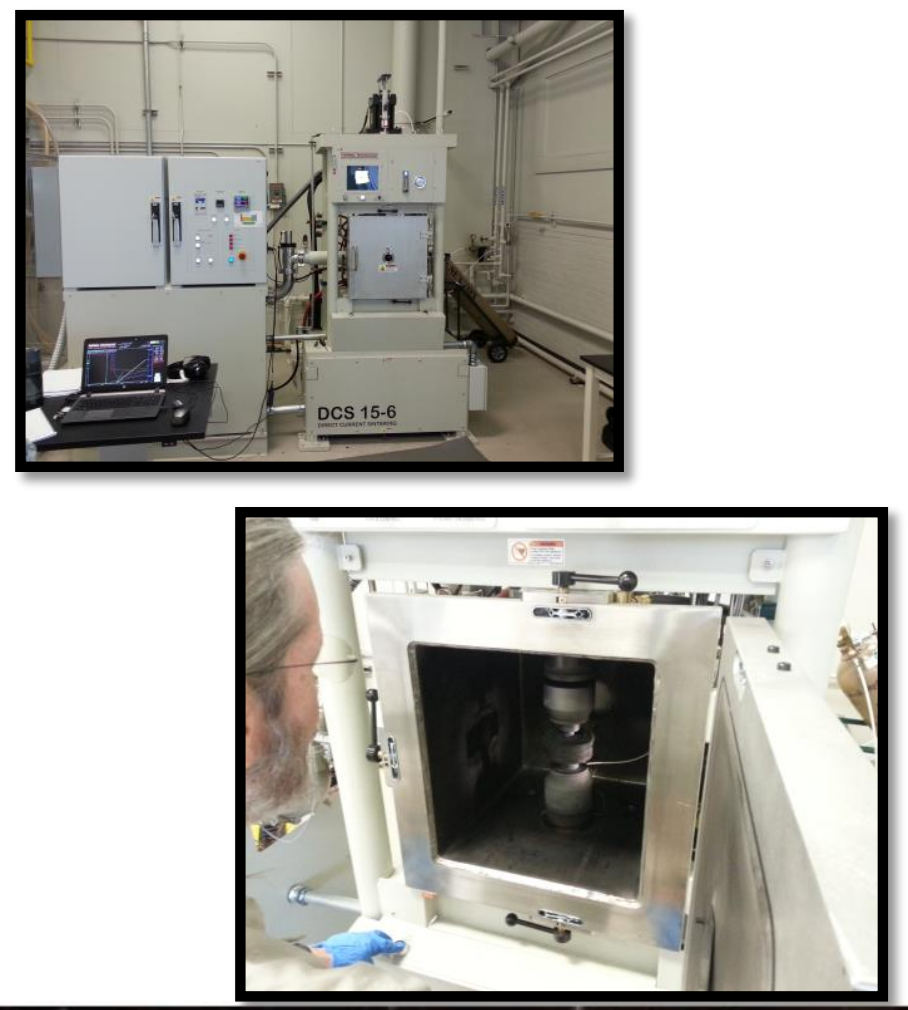


\section{DCS Variables Chart}

Screening Runs of "As Received" $\left[\mathrm{V}_{0.120} \mathrm{Zr}_{0.587} \mathrm{Nb}_{0.293}\right] \cdot \mathrm{C}$

\begin{tabular}{|c|c|c|c|c|c|c|}
\hline Date & $\begin{array}{c}\text { Sintering Temperature } \\
{\left[{ }^{*} \mathrm{C}\right]}\end{array}$ & $\begin{array}{c}\text { Dwell Time } \\
{[\mathrm{min}]}\end{array}$ & $\begin{array}{c}\text { Cooling Rate } \\
{\left[{ }^{*} \mathrm{C} / \mathrm{min}\right]}\end{array}$ & $\begin{array}{c}\text { Pressure } \\
{[\mathrm{Mpa}]}\end{array}$ & $\begin{array}{c}\text { Density } \\
{[\mathrm{g} / \mathrm{cc}]}\end{array}$ & $\begin{array}{c}\% \text { Theoretical } \\
\text { Density }\end{array}$ \\
\hline $1 / 27 / 2017$ & 1500 & 10 & 100 & 50 & 5.65 & $80.77 \%$ \\
\hline $1 / 31 / 2017$ & 1500 & 10 & 100 & 50 & 5.75 & $82.20 \%$ \\
\hline $2 / 1 / 2017$ & 1600 & 10 & 100 & 50 & 5.86 & $83.77 \%$ \\
\hline $2 / 2 / 2017$ & 1600 & 20 & 100 & 50 & 6.05 & $86.48 \%$ \\
\hline $2 / 2 / 2017$ & 1600 & 20 & 200 & 50 & 6.52 & $93.20 \%$ \\
\hline $2 / 3 / 2017$ & 1500 & 20 & 50 & 50 & 6.46 & $92.34 \%$ \\
\hline $2 / 13 / 2017$ & 1600 & 20 & 20 & 50 & 6.20 & $88.62 \%$ \\
\hline $2 / 24 / 2017$ & 1600 & 20 & 200 & 50 & 6.65 & $95.06 \%$ \\
\hline $3 / 17 / 2017$ & 1600 & 20 & 200 & 50 & 6.60 & $94.35 \%$ \\
\hline $3 / 20 / 2017$ & 1700 & 20 & 200 & 50 & 6.80 & $97.21 \%$ \\
\hline $3 / 21 / 2017$ & 1550 & 30 & 200 & 50 & 6.83 & $97.64 \%$ \\
\hline $3 / 22 / 2017$ & 1600 & 20 & 200 & 50 & 6.87 & $98.21 \%$ \\
\hline $3 / 27 / 2017$ & 1600 & 20 & 200 & 60 & 6.85 & $97.92 \%$ \\
\hline
\end{tabular}

- Direct Current Sintering Variables and the resulting density of sample 


\section{9 \% Theoretical Density Plots}
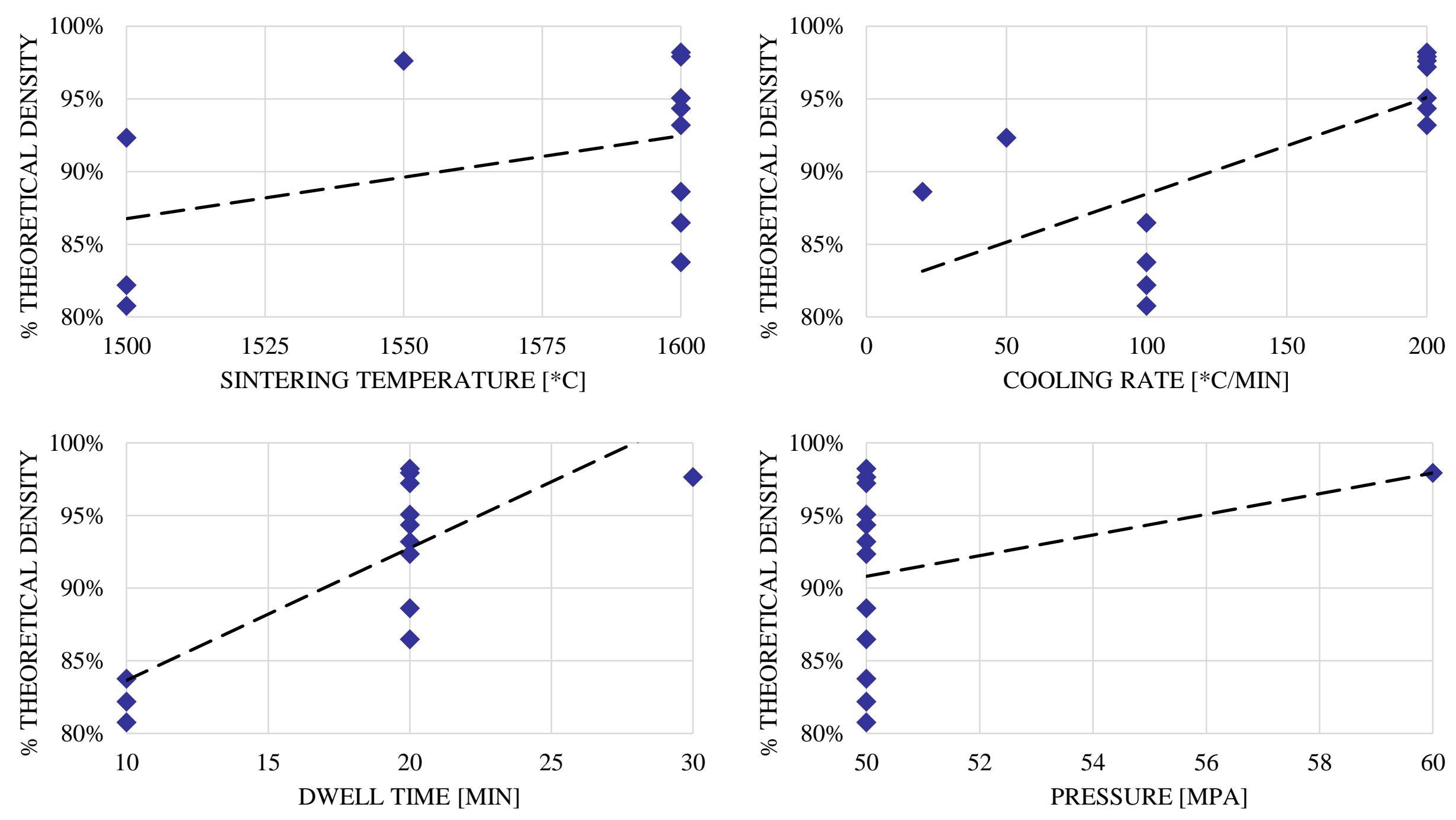


\section{A Fabrication Experiments - Results to Date}

\begin{tabular}{|c|c|c|c|c|c|c|}
\hline \multicolumn{5}{|c|}{ Table 1: X-Ray Spectroscopy Analysis of Fiqure 16 } \\
\hline Material \% & C & O & V & $\mathrm{Zr}$ & $\mathrm{Nb}$ \\
\hline Spectrum 1 & 23.47 & & 66.41 & 6.71 & 3.41 \\
\hline Spectrum 2 & 26.59 & 1.32 & 0.24 & 67.92 & 3.94 \\
\hline Spectrum 3 & 25.62 & 0.92 & 0.31 & 68.95 & 4.20 \\
\hline Spectrum 4 & 25.48 & 1.21 & 0.38 & 68.81 & 4.12 \\
\hline Spectrum 5 & 34.74 & 1.85 & & 22.79 & 40.63 \\
\hline Spectrum 6 & 35.56 & 1.93 & 0.25 & 22.75 & 39.51 \\
\hline Spectrum 7 & 31.71 & 2.62 & 0.39 & 26.76 & 38.52 \\
\hline
\end{tabular}

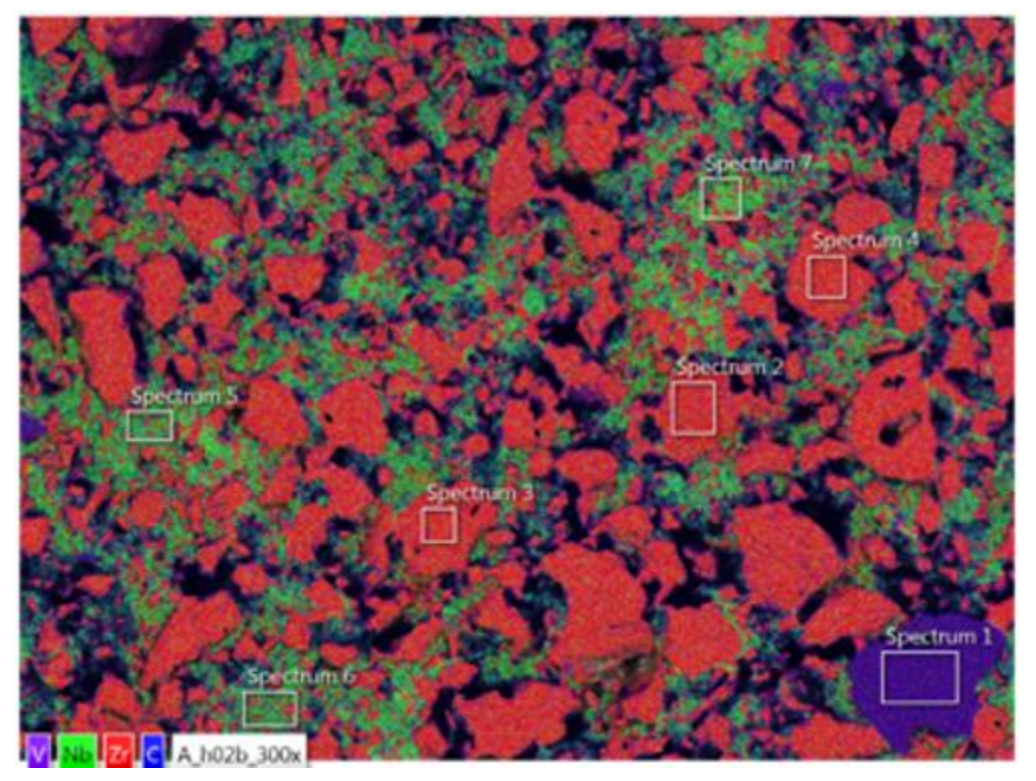

- Early samples showed less than optimal distribution

- Clumps of elements in different regions 


\section{年 Fabrication Experiments - Results to Date.}

\begin{tabular}{|c|c|c|c|c|c|c|c|}
\hline$\%$ & $\Omega$ & 그 & $<$ & 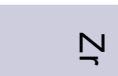 & z & $\stackrel{I}{\Rightarrow}$ & ل1 \\
\hline 8 & 18.1 & 80.8 & 0 & 0.31 & & & \\
\hline 9 & 18.24 & 1.15 & 78.26 & 0.36 & 0.99 & & \\
\hline 10 & 18.56 & 0.49 & 78.29 & 0.65 & 1.32 & & \\
\hline 11 & 18.94 & & 2.1 & 31.08 & 29.87 & & 15.91 \\
\hline 12 & 16.06 & & 3.04 & 25.52 & 33.76 & 21.61 & \\
\hline 13 & 18.77 & & 0.19 & 77.83 & 3.21 & & \\
\hline 14 & 17.67 & & 0.44 & 73.07 & 8.81 & & \\
\hline 15 & 19.32 & & 1.69 & 47.06 & 30.15 & & \\
\hline
\end{tabular}

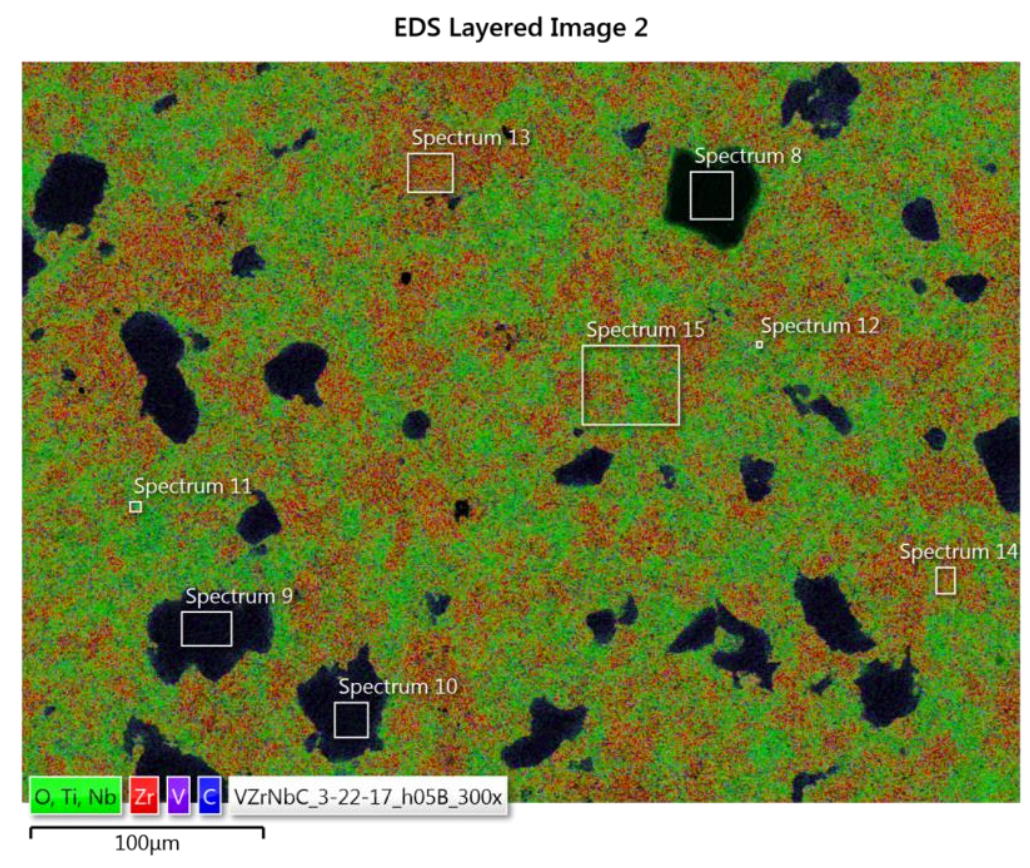

- Sifting materials has improved distribution

- Micro milling has only recently begun but is expected to improve distribution

- Visual inspection seems to show improved distribution, but samples have fractured for unknown reasons 


\section{CARBIDE MATERIAL CHARACTERIZATION}


- The team is attempting to measure thermal diffusivity to fill in gaps in the literature

- Disintegration of the first samples occurred for unknown reasons

- Reasons are unknown, but it should be noted that samples survived much higher temperatures in CFEET

- Future measurement attempts are planned

THERMAL DIFFUSIVITY

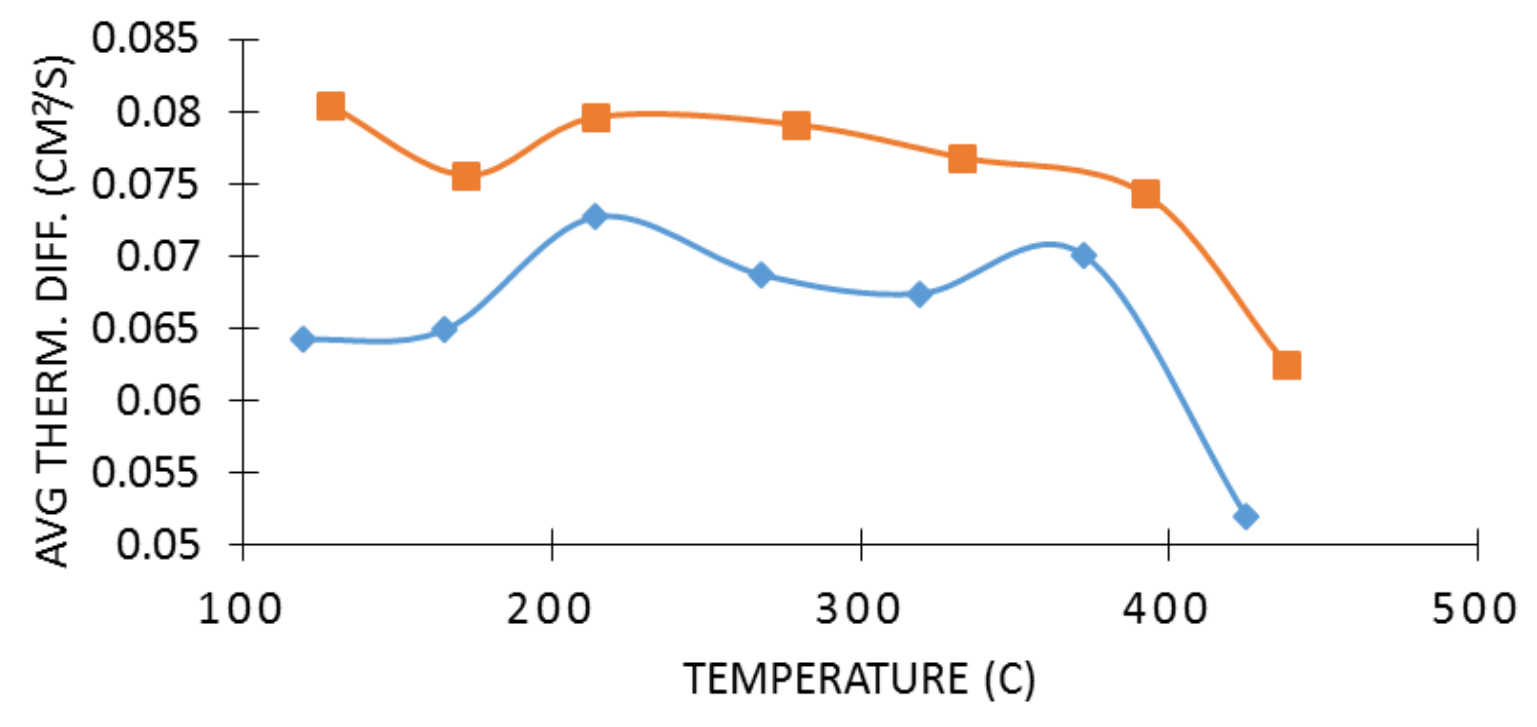




\section{年 Hot Hydrogen Environment Testing}

- Samples tested in Compact Fuel Element Environmental Test (CFEET) system at MSFC

- $50 \mathrm{~kW}$ induction power supply and two-color pyrometers for temperature measurements up to $3000^{\circ} \mathrm{C}$

- Designed to flow hydrogen across subscale fuel materials for testing at high temperatures for up to ten hours.

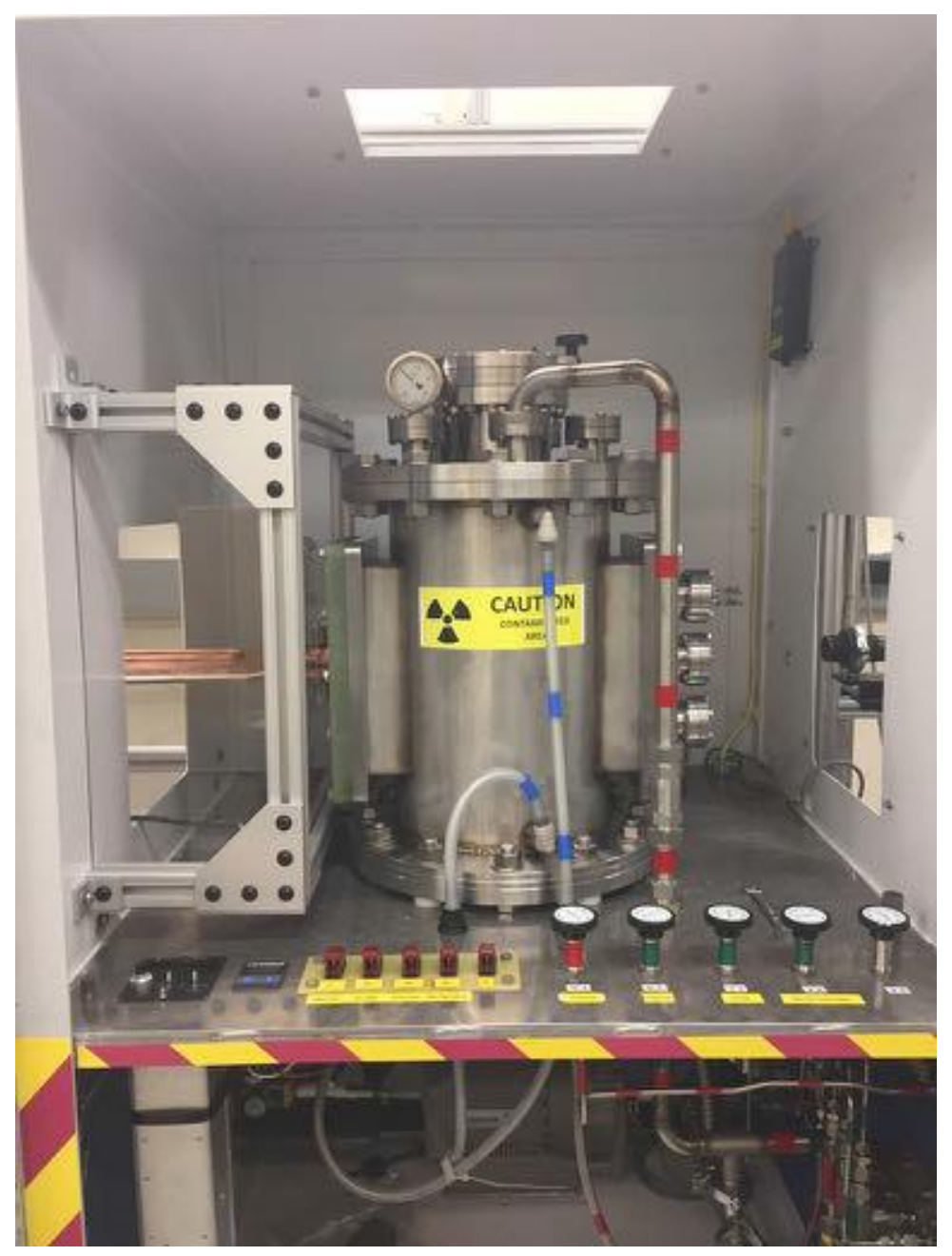




\section{hot Hydrogen Environment Testing}

\section{- CFEET Results}

- $1^{\text {st }}$ sample maintained structural integrity for 30 minutes at $2000 \mathrm{~K}$

- $2^{\text {nd }}$ set of three samples were run at $2250 \mathrm{~K}$ for 30 minutes

- X-ray diffraction (XRD) analysis appears to show the tricarbides moving toward a solid solution

- Unidentified peaks need further analysis to verify if they are due to the formation of free carbon, $\mathrm{ZrC2}$, or other lower melting temperature compounds
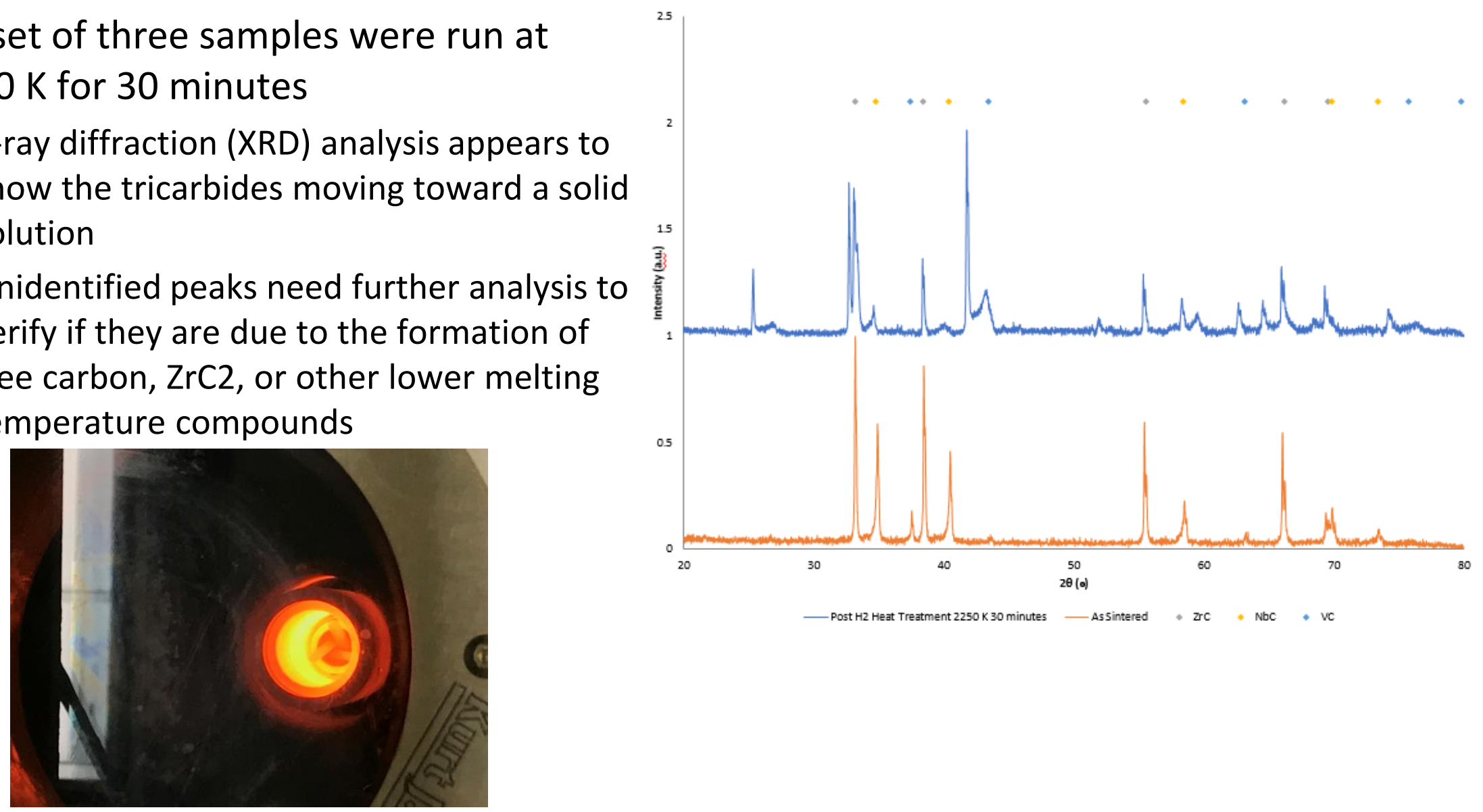


\section{Conclusions}

- Results of this work are promising

- Fabrication has come a long way in showing a viable means for producing these tricarbide rings

- High densities reached

- Micro milling expected to lead to better distribution

- Appears to be moving toward a solid solution after an extended period in a hot hydrogen environment

- Thermal diffusivity measurements are expected from future samples

- Tricarbide samples have held up in a hot hydrogen environment

- Future hotter tests are planned

- The use of tricarbide fuels and this geometry have potential and warrant further investigation 